\title{
Reinekea blandensis sp. nov., a marine, genome-sequenced gammaproteobacterium
}

\author{
Correspondence \\ David R. Arahal \\ arahal@uv.es
}

\author{
Jarone Pinhassi, ${ }^{1}$ María J. Pujalte, ${ }^{2,3}$ M. Carmen Macián, ${ }^{3,4}$ \\ Itziar Lekunberri, José M. González, ${ }^{6}$ Carlos Pedrós-Alió ${ }^{5}$ \\ and David R. Arahal ${ }^{3,4}$
}

\author{
${ }^{1}$ Marine Microbiology, Department of Biology and Environmental Sciences, University of Kalmar, \\ SE-39182 Kalmar, Sweden \\ ${ }^{2}$ Instituto Cavanilles de Biodiversidad y Biología Evolutiva, Universitat de València, \\ Campus de Burjassot, 46100 València, Spain \\ ${ }^{3}$ Departamento de Microbiología y Ecología, Universitat de València, Campus de Burjassot, \\ 46100 València, Spain \\ ${ }^{4}$ Colección Española de Cultivos Tipo (CECT), Universitat de València, Campus de Burjassot, \\ 46100 València, Spain \\ ${ }^{5}$ Institut de Ciències del Mar-CMIMA (CSIC), Passeig Marítim de la Barceloneta 37-49, \\ ES-08003 Barcelona, Catalunya, Spain \\ ${ }^{6}$ Departamento de Microbiología y Biología Celular, Facultad de Farmacia, \\ Universidad de La Laguna, La Laguna, Tenerife, Spain
}

The Gammaproteobacteria constitutes one of the predominant groups within the marine bacterioplankton, together with the Alphaproteobacteria and Bacteroidetes, according to data obtained using molecular biological techniques (Giovannoni \& Rappé, 2000). Furthermore, the phylogenetic diversity of cultured and uncultured gammaproteobacteria accounts for $25-44 \%$ of the global marine bacterioplankton diversity, as revealed by analysis of $16 \mathrm{~S}$ rRNA gene sequences reported in public databases (i.e. GenBank) (Hagström et al., 2002). In Blanes Bay in the north-western Mediterranean Sea, gammaproteobacteria account for up to $8 \%$ (and occasionally $50 \%$ ) of the total bacterial community, as shown by catalysed reporter

The GenBank/EMBL/DDBJ accession numbers for the $16 \mathrm{~S}$ rRNA gene sequence and the genome sequence of strain MED297 ${ }^{\top}$ are DQ403810 and AAOE00000000.

Maximum-parsimony and maximum-likelihood phylogenetic trees, based on almost-complete 16S rRNA gene sequences of strain MED297 ${ }^{\top}$ and closely related species, are available as supplementary material with the online version of this paper. deposition fluorescence in situ hybridization (Alonso-Sáez et al., 2007). Phylogenetic analysis of cultured isolates and phylotypes detected by molecular biological techniques revealed that the gammaproteobacteria in Blanes Bay consist of a diverse array of bacteria belonging to genera such as Alteromonas, Pseudoalteromonas, Vibrio, Marinomonas and Marinobacter, and to the SAR86 and NOR5 clades (Alonso-Sáez et al., 2007; I. Lekunberri and C. Pedrós-Alió, unpublished). As a result of attempts to characterize the culture collection comprising marine bacteria isolated at the Blanes Bay Microbial Observatory (Pinhassi et al., 2006; Arahal et al., 2007), a number of novel gammaproteobacteria were found. One among them, strain MED297 ${ }^{\mathrm{T}}$, was subsequently selected for complete sequencing of its genome as part of a survey of phylogenetically and phenotypically distinct bacteria thriving in the marine environment.

In the present study, we describe a novel bacterium, strain MED297 ${ }^{\mathrm{T}}$, isolated from a surface seawater sample from the Blanes Bay Microbial Observatory in the north-western 
Mediterranean Sea $\left(41^{\circ} 40^{\prime} \mathrm{N} 2^{\circ} 48^{\prime}\right.$ E) collected on 13 November 2001. The sample was incubated for $72 \mathrm{~h}$ at $17{ }^{\circ} \mathrm{C}$ in the dark. For strain isolation, $0.1 \mathrm{ml}$ aliquots of a $100 \times$ dilution of sampled seawater (representing an abundance of approximately $1 \times 10^{3}$ c.f.u. $\mathrm{ml}^{-1}$ ) were spread onto ZoBell agar plates. After primary isolation and purification, strain MED297 ${ }^{\mathrm{T}}$ was cultivated at room temperature on the same medium and stored at $-80{ }^{\circ} \mathrm{C}$ in ZoBell's medium with $25 \%(\mathrm{v} / \mathrm{v})$ glycerol.

Whole-genome sequencing was carried out at the J. Craig Venter Institute through the Gordon and Betty Moore Foundation Initiative in Marine Microbiology (https:// research.venterinstitute.org/moore/). Genome sequencing showed the DNA G+C content of strain MED297 ${ }^{\mathrm{T}}$ to be $52.4 \mathrm{~mol} \%$. Sequencing of the genome produced an annotated genome size of approximately 4.51 Mbp (4301 putative open reading frames). The complete 16S rRNA gene sequence of strain MED297 ${ }^{\mathrm{T}}$ was $1530 \mathrm{nt}$ in length. This sequence was compared with public sequences in EMBL by using the BLAST program (National Center for Biotechnology Information; http://www.ncbi.nlm.nih.gov/). Related sequences were further analysed using the program package ARB (Ludwig et al., 2004; http://www.arb-home.de/). Sequence alignments were corrected manually using the sequence editor ARB_EDIT. Phylogenetic analyses using alternative treeing methods (neighbour joining, maximum parsimony and maximum likelihood) and data subsets were performed using the appropriate ARB tools (Ludwig et al., 1998). The tree derived using the neighbour-joining method with Jukes-Cantor corrections is shown in Fig. 1 . Phylogenetic analysis revealed that strain MED297 ${ }^{\mathrm{T}}$ was related to the species Reinekea marinisedimentorum and Saccharospirillum impatiens. However, the low levels of sequence similarity between strain MED297 ${ }^{\mathrm{T}}$ and the type strains of these two species (95.0 and $94.0 \%$, respectively) indicate that they are not related at the species level. Other genera in the Gammaproteobacteria are clearly more distantly related ( $<90 \%$ similarity). The high bootstrap percentages (Fig. 1) and the comparison of local topologies obtained using different treeing methods (see Supplementary Figs S1 and S2, available in IJSEM Online) both confirm that strain MED $297^{\mathrm{T}}$ clusters consistently with $R$. marinisedimentorum in the first instance, and thereafter with S. impatiens.

Strain MED297 $^{\mathrm{T}}$ was subsequently investigated using previously described methods for phenotypic characterization (Macián et al., 2001, 2005). For comparative purposes, R. marinisedimentorum CECT $7208^{\mathrm{T}}$ and S. impatiens CECT $5721^{\mathrm{T}}$ were also included in the study.

Optical microscopy of bacterial cultures on wet mounts showed that cells were highly motile. To determine the cell morphology, strain $\mathrm{MED} 297^{\mathrm{T}}$ was grown at $21^{\circ} \mathrm{C}$ in marine broth 2216 (Difco) until early exponential phase (24-48 $\mathrm{h}$ incubation), at which point cells were fixed with glutaraldehyde and filtered onto polycarbonate filters with a $0.2 \mu \mathrm{m}$ pore size (Nuclepore). Samples were treated using sequential ethanol dehydration steps, critical-point drying with $\mathrm{CO}_{2}$ and silver coating before being viewed in a scanning electron microscope (S-3500N; Hitachi). As seen in Fig. 2, cells of strain MED297 ${ }^{\mathrm{T}}$ appear as single curved rods, $0.3-0.7 \mu \mathrm{m}$ in diameter and $1.2-2.8 \mu \mathrm{m}$ in length. In some cells, the curvature resembles a gentle spiral. Budding can also be seen at the tips of some cells.

Strain MED297 $7^{\mathrm{T}}$ grew on marine agar 2216 (Difco) (MA) as regular, opaque, non-pigmented colonies that did not swarm or luminesce. Strain MED297 ${ }^{\mathrm{T}}$ required seawaterbased media for growth and was unable to grow on salt tolerance agar (tryptone, $1 \%, \mathrm{w} / \mathrm{v}$; yeast extract, $0.3 \%, \mathrm{w} / \mathrm{v}$; agar, $1.5 \%, \mathrm{w} / \mathrm{v}$ ) with the addition of sodium chloride or potassium chloride. However, growth was obtained when

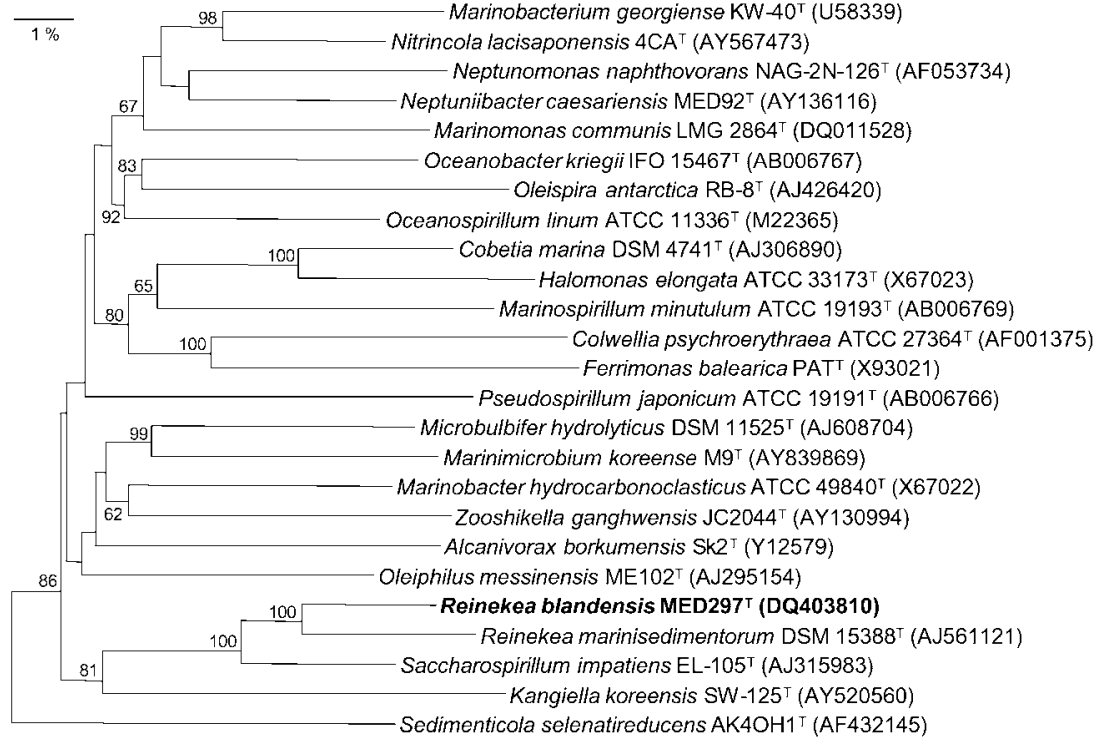

Fig. 1. Neighbour-joining phylogenetic tree based on almost-complete 16S rRNA gene sequences of strain MED297 ${ }^{\top}$ and closely related species. Bootstrap percentages (based on 1000 resamplings) greater than $60 \%$ are shown at branch points. Sequence accession numbers are given in parentheses. Bar, 1 estimated substitution per 100 nucleotide positions. 


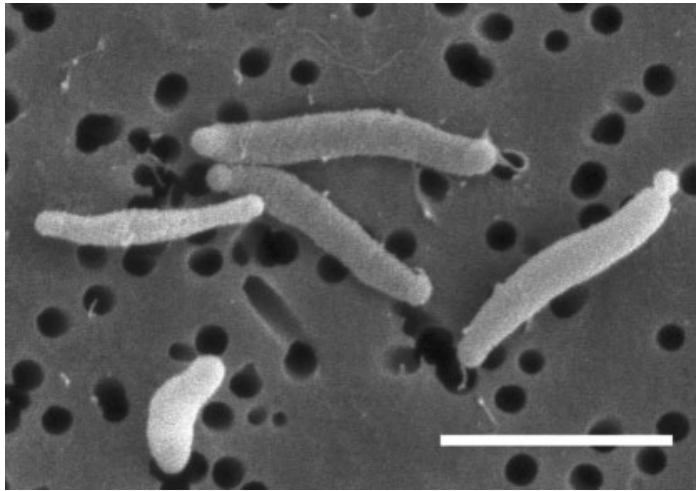

Fig. 2. Cellular morphology of strain MED297 ${ }^{\top}$ in exponential growth phase. Scanning electron microscopy images of cells immobilized on polycarbonate filter $(0.2 \mu \mathrm{m}$ pore size $)$. Bar, $2 \mu \mathrm{m}$.

$\mathrm{Na}^{+}$ions were added together with divalent ions $\mathrm{Mg}^{2+}$ or $\mathrm{Ca}^{2+}$ ) or when $\mathrm{Na}^{+}, \mathrm{K}^{+}, \mathrm{Mg}^{2+}$ and $\mathrm{Ca}^{2+}$ were present in the medium. The salinity range that supported growth on diluted MA or in MA supplemented with $\mathrm{NaCl}$, as reported by Macián et al. (2005), was between 0.3 and $12 \%(\mathrm{w} / \mathrm{v})$ total salts. Thus, strain MED297 ${ }^{\mathrm{T}}$ is a slight halophile with complex ionic requirements. In contrast, $R$. marinisedimentorum CECT $7208^{\mathrm{T}}$ and S. impatiens CECT $5721^{\mathrm{T}}$ only require sodium ions and exhibit different salinity ranges (Table 1). Strain MED297 ${ }^{\mathrm{T}}$ is mesophilic, growing at $15-$ $42{ }^{\circ} \mathrm{C}$, but not at 4 or $45{ }^{\circ} \mathrm{C}$ on MA. Again, $R$. marinisedimentorum CECT $7208^{\mathrm{T}}$ and S. impatiens CECT $5721^{\mathrm{T}}$ have narrower ranges.

Strain MED297 ${ }^{\mathrm{T}}$ was found to be oxidase- and catalasepositive and unable to grow under anaerobic conditions through either glucose fermentation or nitrate respiration. The same results were obtained with $S$. impatiens CECT $5721^{\mathrm{T}}$. In the case of $R$. marinisedimentorum CECT $7208^{\mathrm{T}}$, anaerobic growth through glucose fermentation was obtained, in agreement with the original description (Romanenko et al., 2004). Strain MED297 ${ }^{\mathrm{T}}$ was negative for arginine dihydrolase, ornithine decarboxylase and indole production from tryptophan. It was able to hydrolyse DNA, casein, starch and Tween 80 , but not alginate, agar or lecithin. The strain was unable to grow on marine broth 2216 with $12 \%(\mathrm{w} / \mathrm{v})$ gelatin. The API ZYM (bioMérieux) gallery was used to determine the enzymic activities of the strain; the gallery was used according to the manufacturer's instructions, except that the cells were suspended in a $3.5 \%$ sea salts solution prior to addition to the API ZYM strips, and the strips were incubated for $20 \mathrm{~h}$ at $26{ }^{\circ} \mathrm{C}$. The range of enzymic activities for strain MED297 ${ }^{\mathrm{T}}$ was broader than that for $R$. marinisedimentorum CECT $7208^{\mathrm{T}}$, but similar to that for S. impatiens CECT $5721^{\mathrm{T}}$ (Table 1 ).

The utilization of sugars, alcohols and organic acids as sole carbon and energy sources was analysed in basal medium agar (BMA) [50 mM Tris/ $\mathrm{HCl}(\mathrm{pH} 7.5), 19 \mathrm{mM} \mathrm{NH}_{4} \mathrm{Cl}$, $0.33 \mathrm{mM} \mathrm{K} \mathrm{HPO}_{4} \cdot 3 \mathrm{H}_{2} \mathrm{O}$ and $0.1 \mathrm{mM} \mathrm{FeSO} \cdot \mathrm{FH}_{2} \mathrm{O}$ on half-strength artificial seawater solidified with $1.3 \%(\mathrm{w} / \mathrm{v})$ purified agar (Oxoid); Baumann \& Baumann, 1981]. Amino acids and amines were tested as sole carbon, nitrogen and energy sources on BMA without $\mathrm{NH}_{4} \mathrm{Cl}$. Compounds were added at $2 \mathrm{~g} \mathrm{l}^{-1}$. Positive-control plates were prepared with $5 \mathrm{~g}$ yeast extract $\mathrm{l}^{-1}$, while negativecontrol medium consisted of BMA. Growth was monitored for 12 days. About half of the compounds tested enabled growth of strain MED297 ${ }^{\mathrm{T}}$. The preferred sources were as follows, in decreasing order of preference: organic acids, sugars, alcohols and then amino acids. Compared to strain MED297 ${ }^{\mathrm{T}}$, S. impatiens and R. marinisedimentorum used much narrower ranges of utilizable resources and showed different substrate preferences (Table 1).

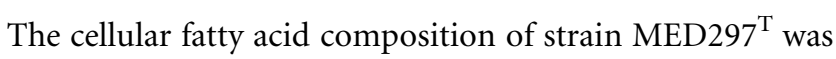
determined by GLC at the Deutsche Sammlung von Mikroorganismen und Zellkulturen (DSMZ; Braunschweig, Germany), as described previously (Kämpfer \& Kroppenstedt, 1996). Analyses of the polar lipids and respiratory quinones of strain $\mathrm{MED} 297^{\mathrm{T}}$ were carried out by the Identification Service of the DSMZ and Dr B. J. Tindall (DSMZ). The results are presented in the species description and in Table 2. Although some differences can be found between the cellular fatty acid and polar lipid profiles of strain MED297 ${ }^{\mathrm{T}}$ and those of $R$. marinisedimentorum and S. impatiens, they all exhibited the same major quinone, Q-8, and the polar lipids phosphatidylglycerol, phosphatidylethanolamine and diphosphatidylglycerol. Strain MED297 ${ }^{\mathrm{T}}$ and $R$. marinisedimentorum, but not S. impatiens, contained phosphatidylinositol. In general, it seems that the chemotaxonomic data are in agreement with the phylogenetic results in the sense that strain $\mathrm{MED} 297^{\mathrm{T}}$ is more closely related to $R$. marinisedimentorum than to S. impatiens.

The low levels of $16 \mathrm{~S}$ rRNA gene sequence similarity between strain MED297 ${ }^{\mathrm{T}}$ and any other established species warrants its consideration as a separate species. The organisms most closely related to strain MED $297^{\mathrm{T}}$ are $R$. marinisedimentorum DSM $15388^{\mathrm{T}}$ and S. impatiens EL$105^{\mathrm{T}}$ (95 and $94 \%$ sequence similarity, respectively); all others were clearly more distant. As discussed above, all three organisms differ in terms of a significant number of phenotypic traits. Thus, two possibilities seem reasonable: one is that strain MED297 ${ }^{\mathrm{T}}$ represents a novel genus and species; the other, which is more conservative, is that MED297 ${ }^{\mathrm{T}}$ represents a novel species within one of these two genera (Reinekea or Saccharospirillum). Because the phylogenetic analyses revealed that strain MED297 ${ }^{\mathrm{T}}$ clustered consistently with $R$. marinisedimentorum DSM $15388^{\mathrm{T}}$ in the first instance, and because these two organisms also shared some phenotypic traits, including chemotaxonomic ones, strain MED297 ${ }^{\mathrm{T}}$ should be classified within a novel species of the genus Reinekea, for which the name Reinekea blandensis sp. nov. is proposed. 
Table 1. Phenotypic characteristics that differentiate strain MED297 ${ }^{\top}$ from closely related species.

Strains: 1, MED297 ${ }^{\mathrm{T}}$; 2, R. marinisedimentorum CECT $7208^{\mathrm{T}}$; 3, S. impatiens CECT $5721^{\mathrm{T}}$. +, Positive; -, negative; w, weakly positive. Data were obtained in this study unless indicated otherwise. None of the strains produced indole from tryptophan or hydrolysed lecithin. All strains used Dglucose, D-fructose, D-galactose (weakly), maltose, cellobiose, sucrose, melibiose (weakly), glycerol and pyruvate as sole energy and carbon sources. None of the strains was able to use D-ribose, D-xylose, trehalose, L-rhamnose, amygdalin, D-glucuronate, D-galacturonate, myo-inositol, D-sorbitol, D-saccharate, D-glycerate, glycine, L-serine, L-threonine, trans-aconitate, L-citrulline, L-histidine, L-lysine, L-sarcosine, betaine or putrescine as sole energy and carbon sources. None of the strains showed trypsin, $\alpha$-chymotrypsin, $\alpha$-galactosidase, $\beta$-glucuronidase, $N$-acetyl- $\beta$-glucosaminidase, $\alpha$ mannosidase or $\alpha$-fucosidase activities in the API ZYM system.

\begin{tabular}{|c|c|c|c|}
\hline Characteristic & 1 & 2 & 3 \\
\hline Cell size $(\mu \mathrm{m})$ & $0.3-0.7 \times 1.2-2.8$ & $0.4-0.5 \times 1.5-1.7$ & $0.5-1.0 \times 2.0-12.0$ \\
\hline Growth in anaerobic jar & - & $+^{*}$ & $-{ }^{*}$ \\
\hline Nitrate reduction & $-\dagger$ & + & + \\
\hline Salt range $(\%, \mathrm{w} / \mathrm{v})$ & $0.3-12$ & $0.9-8 \ddagger$ & $0.9-12 \ddagger$ \\
\hline \multicolumn{4}{|l|}{ Hydrolysis of: } \\
\hline Casein & + & - & $+^{*}$ \\
\hline Gelatin & $-\dagger$ & - & + \\
\hline Starch & + & - & $\mathrm{w} \ddagger$ \\
\hline Alginate & - & $\mathrm{w}^{*}$ & $-*$ \\
\hline Tween 80 & + & $-{ }^{\star}$ & 一†t \\
\hline Lactose & + & $-{ }^{*}$ & $\mathrm{w} \ddagger$ \\
\hline Salicin & $\mathrm{w}$ & $-{ }^{*}$ & $-\ddagger$ \\
\hline D-Gluconate & + & - & $+^{*}$ \\
\hline$N$-Acetyl-D-glucosamine & + & - & $+^{*}$ \\
\hline D-Mannitol & + & + & $-{ }^{\star}$ \\
\hline Acetate & + & $\mathrm{w}^{\star}$ & $+^{*}$ \\
\hline Citrate & + & - & $\mathrm{w} \ddagger$ \\
\hline Malate & $\mathrm{w}$ & - & + \\
\hline Butyrate & $\mathrm{w}$ & $-*$ & $\mathrm{w}^{*}$ \\
\hline 2-Ketoglutarate & + & $-*$ & $+^{*}$ \\
\hline Succinate & + & $-{ }^{\star}$ & $-\ddagger$ \\
\hline L-Alanine & - & $-*$ & $\mathrm{w}^{*}$ \\
\hline L-Arginine & + & $-*$ & $\mathrm{w}^{*}$ \\
\hline L-Tyrosine & + & $-*$ & $\mathrm{w}^{*}$ \\
\hline L-Ornithine & $\mathrm{w}$ & $-*$ & $\mathrm{w}^{*}$ \\
\hline$\gamma$-Aminobutyric acid & - & $-*$ & $\mathrm{w}^{*}$ \\
\hline L-Aspartate & - & $-{ }^{*}$ & $+^{*}$ \\
\hline DNA G $+\mathrm{C}$ content $(\mathrm{mol} \%)$ & 52.4 & $51.1^{a} \S$ & $54.6^{b}$ \\
\hline
\end{tabular}

${ }^{\star}$ Traits not determined previously for reference strains.

$\dagger$ No growth in medium.

$\ddagger$ Differs from previously published result(s).

$\S$ Data taken from: $a$, Romanenko et al. (2004); b, Labrenz et al. (2003). 
Table 2. Fatty acid compositions (\%) of strain MED297 ${ }^{\top}$ and R. marinisedimentorum $\mathrm{KMM}^{3655^{\top}}$

Cells were grown on MA at $35{ }^{\circ} \mathrm{C}$ for 3 days. -, Not detected. Data for R. marinisedimentorum $\mathrm{KMM} 3655^{\mathrm{T}}$ were taken from Romanenko et al. (2004).

\begin{tabular}{|c|c|c|}
\hline Fatty acid & ${\operatorname{MED} 297^{T}}^{T}$ & $\begin{array}{l}\text { R. marinisedimentorum } \\
\text { KMM } 3655^{\mathrm{T}}\end{array}$ \\
\hline $14: 0$ & $<1$ & 1.99 \\
\hline $15: 0$ & 2.7 & 4.11 \\
\hline $16: 0$ & 13.97 & 31.61 \\
\hline $17: 0$ & 9.07 & 5.94 \\
\hline $18: 0$ & $<1$ & $<1$ \\
\hline $15: 1 \omega 6 c$ & $<1$ & - \\
\hline $16: 1 \omega 7 c$ & $21.48^{*}$ & 26.72 \\
\hline $17: 1 \omega 6 c$ & 5.40 & 1.89 \\
\hline $17: 1 \omega 8 c$ & 5.39 & 1.29 \\
\hline $18: 1 \omega 7 c$ & 14.59 & 19.04 \\
\hline $12: 0$ ALDE & $<1$ & $<1$ \\
\hline $14: 0$ iso & $<1$ & - \\
\hline $15: 0$ iso & $<1$ & - \\
\hline $16: 0$ iso & 17.25 & - \\
\hline $17: 0$ iso & $<1$ & - \\
\hline 17:0 10-methyl & - & $<1$ \\
\hline $18: 0$ iso & 4.54 & - \\
\hline $18: 1$ iso & 1.28 & - \\
\hline $14: 03-\mathrm{OH}$ & 1.21 & 2.35 \\
\hline $15: 03-\mathrm{OH}$ & $<1$ & - \\
\hline $16: 0 \mathrm{~N}$ alcohol & - & 1.21 \\
\hline $16: 1 \omega 7 c$ alcohol & - & 1.09 \\
\hline
\end{tabular}

${ }^{\star}$ Identified as $16: 1 \omega 7 c / 15: 0$ iso $2-\mathrm{OH}$ (summed feature 3 ).

\section{Description of Reinekea blandensis sp. nov.}

Reinekea blandensis (blan.den'sis. L. fem. adj. blandensis pertaining to Blande or Blanda, the name the Romans used for the city of Blanes, which has given its name to the Bay of Blanes, where the type strain was isolated).

Gram-negative, strictly aerobic, chemo-organotrophic bacterium. Oxidase- and catalase-positive. Cells are straight or slightly bent motile rods, $0.3-0.7 \mu \mathrm{m}$ in diameter and 1.2$2.8 \mu \mathrm{m}$ long. Gas vesicles are not observed. Poly- $\beta$-hydroxybutyrate granules are produced. Carbohydrates are not fermented. Nitrate is not reduced to nitrite or $\mathrm{N}_{2}$. At least $0.3 \%(\mathrm{w} / \mathrm{v})$ marine salts is required; up to $12 \%(\mathrm{w} / \mathrm{v})$ salts is tolerated. Positive for growth at $15-42{ }^{\circ} \mathrm{C}$. No growth detected at 4 or $45{ }^{\circ} \mathrm{C}$. Casein, starch, Tween 80 and DNA are hydrolysed. Does not hydrolyse gelatin (no growth in medium), alginate, agar or lecithin. Negative for arginine dihydrolase, ornithine decarboxylase and indole production from tryptophan. Utilizes the following compounds as carbon and energy sources: L-arabinose, D-glucose, Dfructose, D-mannose, maltose, cellobiose, sucrose, lactose, $\mathrm{N}$-acetyl-D-glucosamine, glycerol, D-mannitol, D-gluconate, propionate, pyruvate, acetate, citrate, 2-ketoglutarate, succinate, fumarate, lactate, DL- $\beta$-hydroxybutyrate, L-leucine, L-tyrosine and L-arginine. Weakly positive results are obtained on D-galactose, melibiose, salicin, butyrate, malate, L-glutamate and L-ornithine. Growth is negative on D-ribose, D-xylose, trehalose, L-rhamnose, amygdalin, D-glucuronate, D-galacturonate, myo-inositol, D-sorbitol, D-saccharate, Dglycerate, glycine, L-serine, L-threonine, L-alanine, transaconitate, $\gamma$-aminobutyric acid, L-citrulline, L-histidine, Laspartate, L-lysine, L-sarcosine, betaine and putrescine. Major cellular fatty acids are, in decreasing order of abundance, $16: 1 \omega 7 c / 15: 0$ iso $2-\mathrm{OH}, 16: 0$ iso, $18: 1 \omega 7 c$ and $16: 0$. The whole pattern and relative abundances are given in Table 2 . Polar lipids consist of phosphatidylglycerol, phosphatidylethanolamine, diphosphatidylglycerol, phosphatidylinositol, three unidentified phospholipids, an unknown aminolipid and a lipid. Main respiratory quinone is Q-8 (92\%); Q-9 is present in minor amounts. The DNA G+C content of the type strain is $52.4 \mathrm{~mol} \%$.

The type strain, MED $297^{\mathrm{T}}$ (=CECT $7120^{\mathrm{T}}=\mathrm{CCUG}$ $\left.52066^{\mathrm{T}}\right)$, was isolated from surface water from the Mediterranean Sea.

\section{Acknowledgements}

This work was supported by the Swedish Science Council (project 621-2003-2692, to J.P.), the Spanish Ministerio de Educación y Ciencia (project CGL-2005-02292, to M. J.P.) and by the Consellería d'Empresa, Universitat i Ciencia (project ACOMP2006/177, to M.J.P.). D. R.A. has a contract with the Universitat de València under the Ramón y Cajal program (Ministerio de Educación y Ciencia).

\section{References}

Alonso-Sáez, L., Balagué, V., Sà, E. L., Sánchez, O., González, J. M., Pinhassi, J., Massana, R., Pernthaler, J., Pedrós-Alió, C. \& Gasol, J. M. (2007). Seasonality in bacterial diversity in north-west Mediterranean coastal waters: assessment through clone libraries, fingerprinting and FISH. FEMS Microbiol Ecol 60, 98-112.

Arahal, D. R., Lekunberri, I., González, J. M., Pascual, J., Pujalte, M. J., Pedrós-Alió, C. \& Pinhassi, J. (2007). Neptuniibacter caesariensis gen. nov., sp. nov., a novel marine genome-sequenced gammaproteobacterium. Int J Syst Evol Microbiol 57, 1000-1006.

Baumann, P. \& Baumann, L. (1981). The marine gram-negative eubacteria: genera Photobacterium, Beneckea, Alteromonas, Pseudomonas and Alcaligenes. In The Prokaryotes, vol. 2, pp. 13021331. Edited by M. P. Starr, H. Stolp, H. G. Trüper, A. Balows \& H. Schleger. Berlin: Springer-Verlag.

Giovannoni, S. J. \& Rappé, M. (2000). Evolution, diversity, and molecular ecology of marine prokaryotes. In Microbial Ecology of the Oceans, pp. 47-84. Edited by D. Kirchman. New York: Wiley.

Hagström, Å., Pommier, T., Rohwer, F., Simum, K., Stolte, W., Svensson, D. \& Zweifel, U. L. (2002). Use of 16 S ribosomal DNA for delineation of marine bacterioplankton species. Appl Environ Microbiol 68, 3628-3633.

Kämpfer, P. \& Kroppenstedt, R. M. (1996). Numerical analysis of fatty acid patterns of coryneform bacteria and related taxa. Can J Microbiol 42, 989-1005.

Labrenz, M., Lawson, P. A., Tindall, B. J., Collins, M. D. \& Hirsch, P. (2003). Saccharospirillum impatiens gen. nov., sp. nov., a novel 
$\gamma$-Proteobacterium isolated from hypersaline Ekho Lake (East Antarctica). Int J Syst Evol Microbiol 53, 653-660.

Ludwig, W., Strunk, O., Klugbauer, S., Klugbauer, N., Weizenegger, M., Neumaier, J., Bachleitner, M. \& Schleifer, K.-H. (1998). Bacterial phylogeny based on comparative sequence analysis. Electrophoresis 19, 554-568.

Ludwig, W., Strunk, O., Westram, R., Richter, L., Meier, H., Yadhukumar, Buchner, A., Lai, T., Steppi, S., Jobb, G. \& other authors (2004). ARB: a software environment for sequence data. Nucleic Acids Res 32, 1363-1371.

Macián, M. C., Ludwig, W., Schleifer, K.-H., Garay, E. \& Pujalte, M. J. (2001). Thalassomonas viridans gen. nov., sp. nov., a novel marine $\gamma$ proteobacterium. Int J Syst Evol Microbiol 51, 1283-1289.
Macián, M. C., Arahal, D. R., Garay, E., Ludwig, W., Schleifer, K.-H. \& Pujalte, M. J. (2005). Thalassobacter stenotrophicus gen. nov., sp. nov., a novel marine $\alpha$-proteobacterium isolated from Mediterranean sea water. Int J Syst Evol Microbiol 55, 105-110.

Pinhassi, J., Bowman, J. P., Nedashkovskaya, O. I., Lekunberri, I., Gómez-Consarnau, L. \& Pedrós-Alió, C. (2006). Leeuwenhoekiella blandensis sp. nov., a genome-sequenced marine member of the family Flavobacteriaceae. Int $J$ Syst Evol Microbiol 56, 1489-1493.

Romanenko, L. A., Schumann, P., Rohde, M., Mikhailov, V. V. \& Stackebrandt, E. (2004). Reinekea marinisedimentorum gen. nov., sp. nov., a novel gammaproteobacterium from marine coastal sediments. Int J Syst Evol Microbiol 54, 669-673. 